\section{Job satisfaction backed by training}

The opportunity to take on a challenge and learn new skills should never be underestimated when it comes to workplace satisfaction, according to Rodericks Dental.

There have to be development and promotional opportunities - or at the very least, a chance to take a new course or gain additional qualifications - if you are to make the most of your skills and expertise.

That's why at Rodericks Dental all staff have access to a wide range of $\mathrm{CPD}$ and training courses, with discounted rates available for a number of external sessions and qualifications across all specialisms.

Internal regional sessions are also available to provide an ongoing learning continuum on a variety of staple subjects, such as medico-legal matters and infection control.

Rodericks says it has always prided itself on ensuring that all members of the team have the right support and chance to develop, and will continue to encourage professional development long into the future to ensure a satisfied workplace.

More information is available by visiting www.rodericksdental. co.uk/careers or by emailing opportunity@rodericksdental. co.uk or by calling 01604602491 (option 1) and ask for Christina Regan in the Dental Recruitment Team.

\section{Growing dental corporate}

The new dental corporate Dental Partners says 2018 is turning out to be a high impact year.

In just seven months, the company already has 29 practices under its wing, successfully positioning itself in the top six UK dental groups.

With only five other dental groups confirmed as owning between 30 and 620 practices in the UK, Dental Partners said its growth was on track to secure the group's place as the UK's fastest growing dental group in 2018.

With practices located throughout the UK - from the south coast, across the Midlands and up to Yorkshire - the network is quickly expanding.

This growth has also opened up job opportunities for the whole dental team, said the company, claiming that it was attracting high quality candidates with a combination of market-leading salary and benefits, flexible and family-friendly policies, alongside exemplary training and personal development opportunities.

Dental Partners said it was set to continue to shake up the corporate world with its innovative thinking and unique offering of high-quality treatment for both NHS and private patients.

By providing an excellent working environment and all the assistance needed in terms of equipment, practice marketing and compliance, practices were assured of preserving complete clinical freedom whilst Dental Partners took on the administrative responsibilities, said the firm.

More information is available at www.dentalpartners.co.uk or by emailing contact@dentalpartners.co.uk.

\section{Easy slide flossers for easy flossing}

The Wisdom Clean Between Easy Slide Tensioning Flossers are ideal for helping patients to stay on top of their daily oral health regimes.

The new Waveform Tension Control System holds the tape taut so that it glides smoothly into the smallest of interdental spaces. This makes it easy for patients to remove plaque and food debris from their mouth, for a cleaner, healthier and brighter smile, says the company.

The silk-like tape is designed to be gentle on the gums and maximise comfort for the patient while flossing. It is also shred resistant. With more than 235 years' experience in developing oral health solutions that work, Wisdom Toothbrushes continues to meet the demands of patients to enable them to enjoy the benefits of optimised dental health, says the company.

More information is available by visiting www.wisdomtoothbrushes.com or by calling 01440714800 .

\section{Wipes for ultimate loupes care}

For effective cleaning, disinfection and maintenance of dental loupes, Nuview offers Cleaning and Disinfectant Wipes for Loupes.

Though dental practices are conscientious about disinfecting surfaces between patients, dental loupes can be a neglected area in the cross infection control regime.

\section{These new} alcohol-free, pre-saturated wipes have been designed to offer an accessible solution to regularly cleaning and disinfecting dental loupes without damaging frames and lenses.

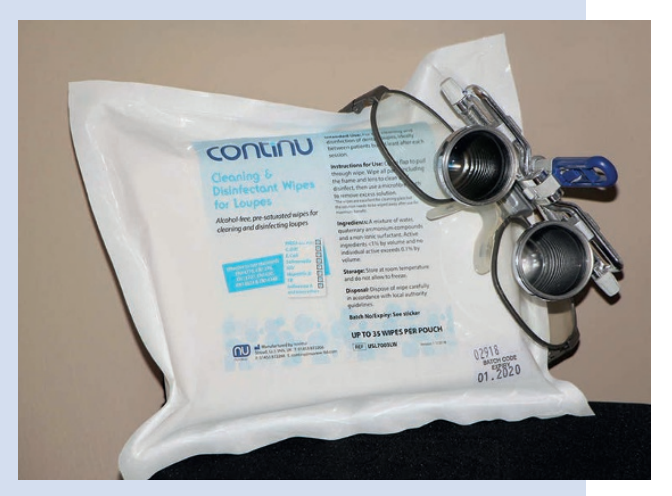

To achieve

optimal results, the company suggests simply wiping all parts of the loupes before using a soft microfibre cloth to remove excess solution to leave the lenses crystal clear.

This can be done quickly and conveniently between patients to maintain the loupes in excellent condition for optimum performance whilst ensuring effective cross infection control to equipment that is exposed to potential cross contamination during treatment.

To order the wipes, either visit Nuview's online shop at www. nuview.co call 01453872266 or email info@nuview-ltd.com. 